\title{
Pengaruh Looseness Terhadap Vibrasi Peralatan Yang Mengalami Unbalance Dan Misalignment
}

\author{
Andi Kurniawan \\ UPDL Suralaya, PLN PUSDIKLAT, Indonesia \\ andi.kurniawan@pln.co.id
}

\begin{abstract}
Looseness occurs in almost all machines and can changes the vibration of the machine. In this paper, experiments were conducted by using two sets of rotor model to observe the effects of looseness on vibration values and patterns on the spectrum of unbalance and misalignment conditions. Rotor model 1 was used to simulate unbalance condition by adding mass to the disk, while rotor model 2 was used to simulate misalignment by changing the position of the bearing housings. Looseness condition was achieved by loosening the bearing housing bolts. The result of vibration observations in unbalance machine showed that looseness changed the overall value and peak values of vibration spectrum. While in machine which has shaft misalignment condition, looseness changed the vibration patterns on the spectrum.
\end{abstract}

Keywords: Looseness, unbalance, misalignment, overall vibration, spectrum

\section{ABSTRAK}

Looseness yang terjadi pada mesin dapat merubah vibrasi mesin dari kondisi sebelumnya. Pada makalah ini eksperimen dilakukan menggunakan dua set rotor model untuk mengamati pengaruh looseness terhadap nilai dan pattern vibrasi pada spektrum kondisi unbalance dan misalignment. Rotor model 1 digunakan untuk mensimulasikan kondisi unbalance dengan menambahkan massa pada disk, sedangkan rotor model 2 digunakan untuk mensimulasikan kondisi misalignment dengan merubah posisi bearing housing. Kondisi looseness dicapai dengan mengendorkan baut bearing housing. Hasil pengamatan vibrasi menunjukkan bahwa looseness pada mesin yang mengalami unbalance akan merubah nilai vibrasi overall dan nilai vibrasi dari peak pada spektrum. Sedangkan pada mesin yang mengalami misalignment, pengaruh looseness lebih dominan ke pola vibrasi pada spektrum.

Kata Kunci: Looseness, unbalance, misalignment, vibrasi overall, spectrum 


\section{PENDAHULUAN}

Looseness merupakan salah satu permasalahan yang sering terjadi pada mesin. Looseness merupakan kondisi ketika terdapat clearance berlebih pada mesin. Baut yang kendor menjadi salah satu penyebab terjadinya looseness. Looseness pada mesin terkadang merupakan reaksi dari permasalahan lain seperti unbalance, misalignment, eksentrisitas, kerusakan bearing dan lainnya [1]. Dengan melakukan pengukuran vibrasi dan analisa pola vibrasi yang terjadi pada mesin, maka penyebab permasalahan pada mesin dapat diidentifikasi. Looseness yang terjadi pada mesin dapat merubah nilai dan pola vibrasi mesin dari kondisi sebelum looseness.

Banyak peneliti dari berbagai kalangan yang tetarik untuk melakukan penelitian terhadap kondisi unbalance, misalignment maupun looseness. Sutar et al [2] melakukan studi kasus beberapa permasalahan vibrasi pada rotating machine dan melakukan analisa frekuensi serta phase untuk mengetahui penyebab terjadinya vibrasi. Saleem et al [3] menemukan metode untuk mendeteksi unbalance pada mesin rotari menggunakan "Deflected Shape of Shaft". Yamamoto, Costa dan Sousa [4] mengembangkan suatu metode untuk mendeteksi unbalance dengan cara menggabungkan analisa vibrasi dan FFT menggunakan Programmable Gate Array. Kumar, Diwakar dan Satynarayana [5] melakukan pengamatan kondisi unbalance mesin pada beberapa kecepatan putaran poros. Dang et al [6] melakukan percobaan unbalance pada mesin rotary dan menghitung beberapa koefisen dari tiap percobaan untuk mencari massa koreksi unbalance. Yanto [7] melakukan eksperimen dengan menempatkan massa pada dua disk prototype rotor pada berbagai orientasi sudut untuk mendapatkan lokasi dimana vibrasi unbalance memiliki amplitude terkecil. Senthilkumar dan Sendhilkumar [8] melakukan eksperimen dan menemukan karakteristik frekuensi yang berbeda pada spektrum untuk jenis kopling yang berbeda. Kurniawan [9] melakukan pengamatan pada model mesin rotary yang mengalami misalignment axial dan menemukan bahwa trend vibrasi overall tidak selalu berbanding lurus dengan kenaikan misalignment. Wang, Chen dan Song [10] melakukan pemodelan numerik terhadap mesin yang mengalami looseness untuk menganalisis karakteristik respon asynchronous. Yang et al [11] melakukan eksperimen untuk mengetahui hubungan fatigue dengan umur looseness baut. Wang et al [12] melakukan simulasi looseness menggunakan model rotor dengan beberapa kondisi looseness dan menyimpulkan bahwa waveform vibrasi memiliki bentuk periodic impact, asimetri, dan memiliki beberapa frekuensi. Nataraj dan Baskaran [13] mengemukakan bahwa metode Bartlett Power Spectral Density (BPSD) dapat digunakan untuk melakukan diagnosa permasalahan pada rotor jika ada permasalahan misalignment dan looseness. Wei et al [14] melakukan eksperimen pada rotor system yang mengalami looseness dengan torsional load yang berbeda, kemudian melakukan simulasi perhitungan berdasarkan data eksperimen tersebut. An dan Zhang [15] melakukan eksperimen menggunakan metode mode decomposition untuk mendiagnosa looseness pada rotor system.

Pada makalah ini penulis melakukan sesuatu yang belum terdapat di paper sebelumnya yaitu studi eksperimental pengukuran vibrasi dari rotor model yang mengalami unbalance dan rotor model yang mengalami misalignment. Kedua rotor model tersebut kemudian dibuat looseness pada kecepatan putaran poros yang sama. Tujuannya adalah untuk mengetahui pengaruh looseness terhadap nilai vibrasi overall, dan perubahan pattern vibrasi pada grafik spektrum dari kondisi unbalance dan misalignment. 


\section{Metode Penelitian}

Eksperimen ini menggunakan dua set rotor model yang identik. Gambar 1 menunjukkan rotor model yang digunakan dalam studi eksperimen. Rotor model terdiri dari disk berbahan plastik dengan ketebalan $10 \mathrm{~mm}$ dan diameter $200 \mathrm{~mm}$ tersambung pada rotor dan ditopang oleh deep groove ball bearing. Pada disk terdapat 36 buah lubang untuk menempatkan massa untuk mensimulasikan kondisi unbalance. Pada base plate sisi disk terdapat baut pengatur poisisi bearing housing untuk mensimulasikan kondisi misalignment. Rotor tersebut disambungkan dengan motor induksi $400 \mathrm{~W}$ (0,5 HP) oleh kopling fleksibel. Putaran motor listrik diatur oleh Variable Frequency Drive yang bekerja dengan cara mengatur frekuensi dan voltase listrik yang masuk ke motor. Pada eksperimen ini frekuensi listrik diatur pada $25,8 \mathrm{~Hz}$ sehingga rotor berputar pada kecepatan tetap $1500 \mathrm{rpm}$.

Pengukuran vibrasi dilakukan menggunakan VibXpert II dengan sensor accelerometer yang mempunyai sensitivitas $1 \mu \mathrm{A} /\left(\mathrm{m} / \mathrm{s}^{2}\right)$. Pengukuran putaran rotor dilakukan menggunakan laser triger sensor. Data vibrasi yang diukur adalah data overall dan grafik spektrum.

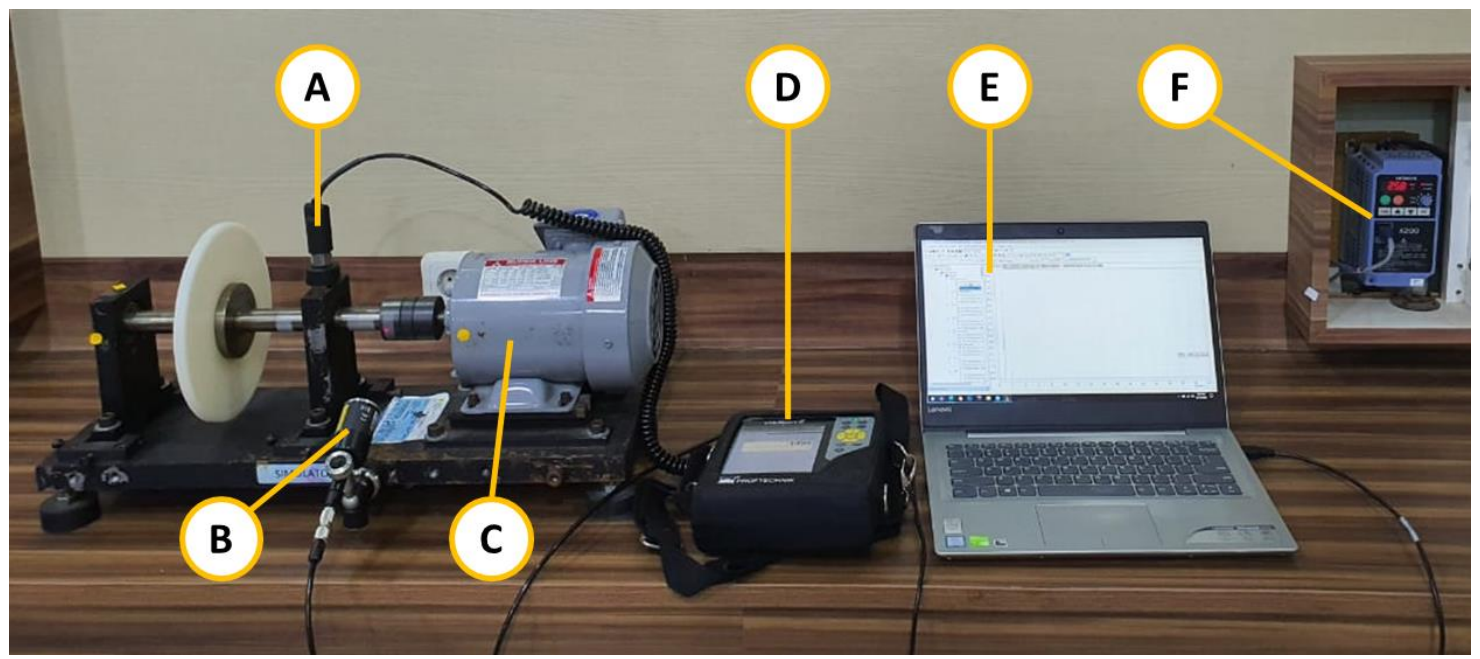

Gambar 1. Konfigurasi Eksperimen. A, Accelerometer Sensor ; B, Laser Triger Sensor ; C, Rotor Model ; D, Vibration Analyzer; E, Software Data Management ; F, Variable Frequency Drive

Sebagai data awal, pengukuran vibrasi dilakukan pada saat rotor model sudah dilakukan alignment dan tidak ada massa unbalance. Rotor model 1 digunakan untuk mengetahui pengaruh looseness pada unbalance. Kondisi unbalance didapatkan dengan menambahkan massa sebesar 4,489gram pada disk. Kemudian pengukuran vibrasi dilakukan untuk mengetahui nilai dan pattern vibrasi, Setelah itu rotor model dibuat looseness dengan mengendorkan baut baseplate bearing housing disk sisi outboard, dan kemudian dilakukan pengukuran vibrasi.

Untuk mengetahui pengaruh looseness pada misalignment, eksperimen dilakukan pada rotor model 2. Sebagai data awal, pengukuran dilakukan pada kondisi rotor tidak mengalami unbalance maupun misalignment. Pengukuran vibrasi kemudian dilakukan pada kondisi misalignment, yang diperoleh dengan menggeser bearing housing disk sisi inboard ke arah horizontal sebesar $1 \mathrm{~mm}$ dan bearing housing disk sisi outboard ke arah horizontal sebesar $2 \mathrm{~mm}$. Setelah itu pengukuran vibrasi dilakukan pada kondisi looseness, yang diperoleh dengan mengendorkan baut baseplate bearing housing disk sisi outboard. 


\section{HASIL DAN PEMBAHASAN}

Gambar 2 menunjukkan data nilai vibrasi overall dari tiap measurement point pada rotor model. Pada kondisi normal tanpa adanya massa unbalance dan misalignment poros, vibrasi overall pada tiap titik pengukuran mempunyai nilai di bawah $1 \mathrm{~mm} / \mathrm{s} \mathrm{rms}$. Dengan adanya penambahan massa unbalance pada disk, nilai vibrasi overall pada setiap measurement point menjadi naik. Terlihat bahwa nilai vibrasi tertinggi unbalance terjadi pada bearing Motor Outboard arah horizontal dengan nilai 8,58 mm/s RMS. Kemudian dengan membuat looseness baut pengikat bearing housing disk outboard, nilai vibrasi dari setiap measurement point menjadi turun. Penurunan nilai vibrasi overall terbesar akibat adanya looseness terjadi pada bearing Motor Outboard Horizontal, yaitu dari 8,58 mm/s RMS menjadi 5,62 mm/s RMS.

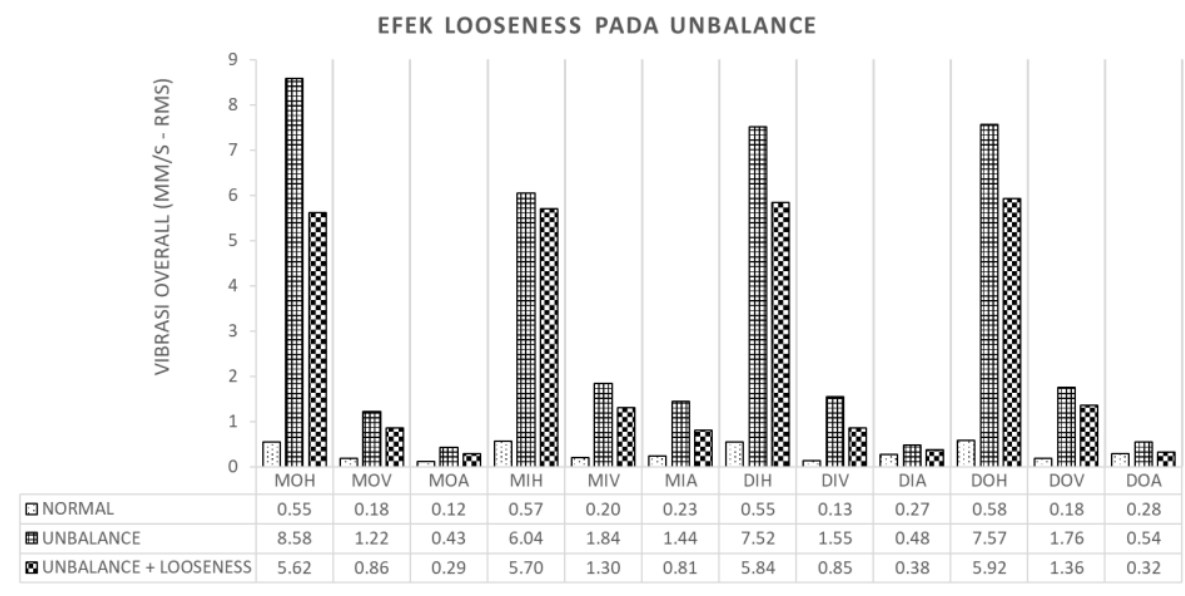

Gambar 2. Pengaruh looseness terhadap nilai vibrasi overall pada unbalance rotor

\section{SPEKTRUM MOTOR}

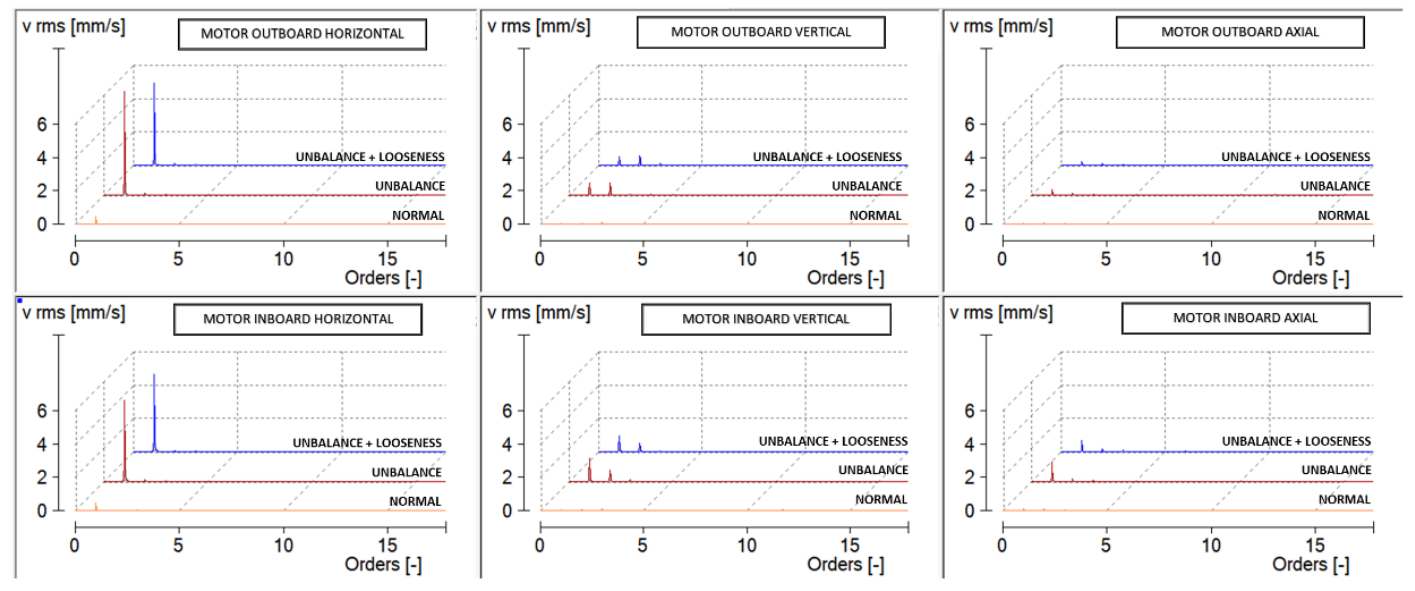

Gambar 3. Grafik spektrum motor kondisi normal, unbalance dan looseness 


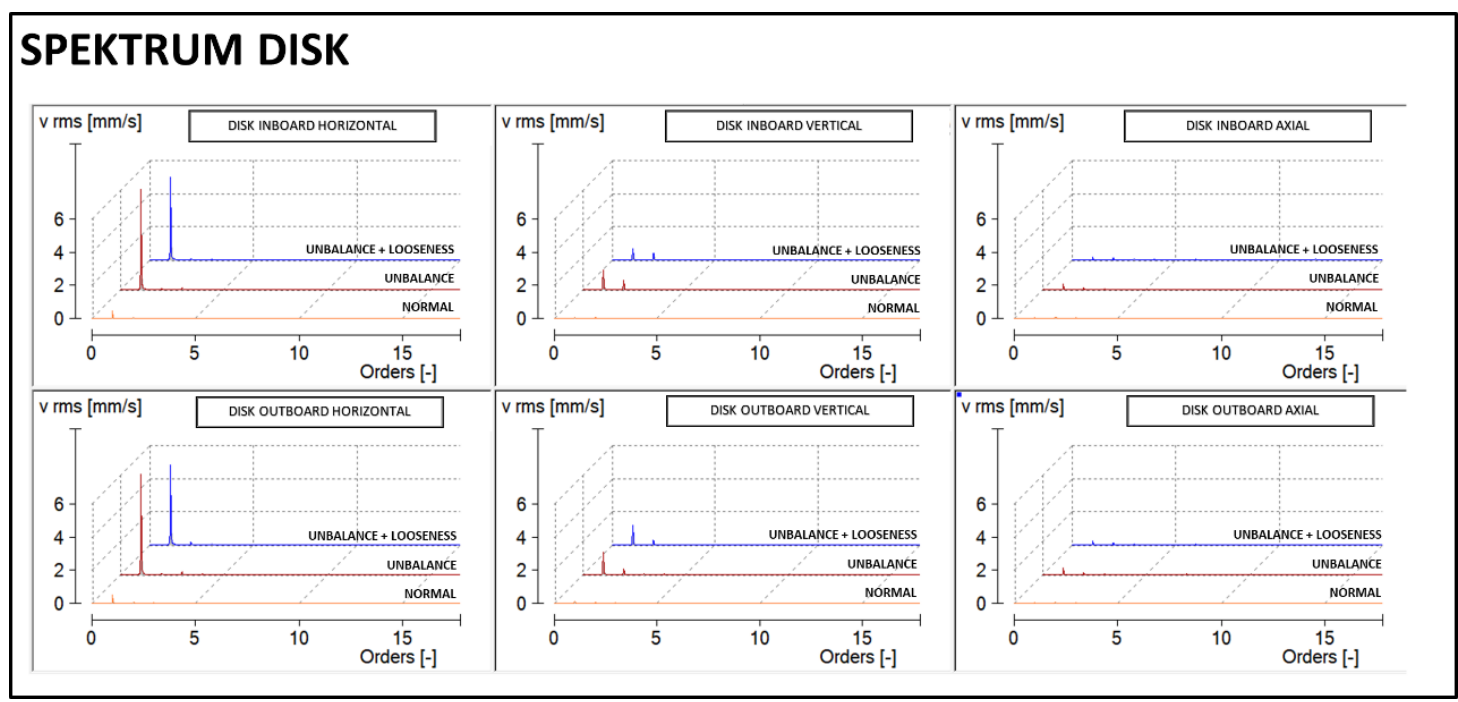

Gambar 4. Grafik spektrum disk kondisi normal, unbalance dan looseness

Gambar 3 dan 4 adalah grafik spektrum vibrasi motor dan disk pada kondisi normal, unbalance dan looseness. Pada kondisi normal, nilai vibrasi pada masing-masing measurement point sangat kecil. Akan tetapi dengan penambahan massa unbalance sebesar 4,489gram pada disk, menyebabkan nilai vibrasi arah horizontal pada masing-masing bearing naik enam kali lipat dari nilai semula. Vibrasi tertinggi dari semua bearing adalah pada arah horizontal, dengan peak dominan pada spektrum terjadi pada 1x turning speed. Sedangkan vibrasi arah vertikal dan axial relatif kecil apabila dibandingkan dengan arah horizontalnya. Hal ini merupakan ciri khas dari permasalahan unbalance.

Kondisi looseness dicapai dengan cara mengendorkan baut bearing housing sisi disk outboard tanpa melepas massa unbalance pada disk. Dengan adanya looseness pada rotor model, spektrum vibrasi yang ditunjukkan oleh hasil pengukuran mempunyai pattern yang sama dengan kondisi unbalance. Walaupun pattern spektrumnya sama, akan tetapi looseness memberikan pengaruh pada nilai vibrasinya. Looseness pada mesin menurunkan nilai vibrasi dari semua peak yang ada pada spektrum.

Pengamatan pengaruh looseness terhadap kondisi misalignment dilakukan pada rotor model 2. Hasil pengukuran vibrasi overall kondisi normal, misalignment dan looseness dapat dilihat pada gambar 5. Misalignment shaft akan menaikkan nilai vibrasi overall. Kenaikan nilai vibrasi overall tertinggi akibat adanya misalignment shaft adalah pada Motor Inboard Axial yaitu dari $0.7 \mathrm{~mm} / \mathrm{s}$ RMS menjadi $4.04 \mathrm{~mm} / \mathrm{s}$ RMS. Kemudian dengan membuat looseness baut pengikat bearing housing disk outboard, nilai vibrasi overall dari setiap measurement point menunjukkan respon yang beragam. Akan tetapi looseness akan menurunkan nilai overall tertinggi, yaitu pada Motor Inboard Axial dari 4.04 mm/s RMS menjadi $3.36 \mathrm{~mm} / \mathrm{s}$ RMS. 


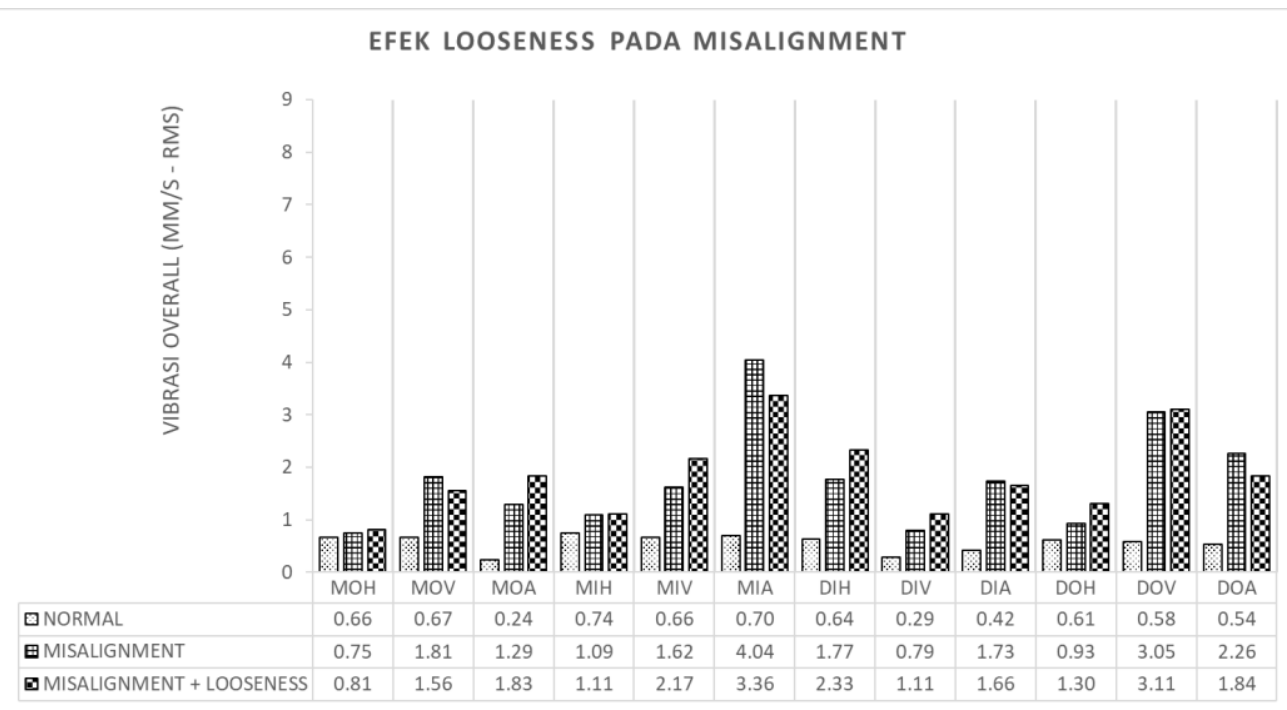

Gambar 5. Pengaruh looseness terhadap nilai vibrasi overall pada misalignment shaft

Gambar 5 dan 6 adalah grafik spektrum motor dan disk pada kondisi normal, misalignment dan looseness. Pada kondisi normal nilai vibrasi pada spektrum sangat kecil, akan tetapi dengan penambahan misalignment axial pada bearing housing disk ke arah horizontal akan menaikkan nilai vibrasi. Nilai vibrasi tertinggi pada spektrum terjadi pada Motor Inboard arah axial dengan peak dominan pada 3x dan 6x rpm mesin. Untuk beberapa measurement point lainnya, pola vibrasi pada spektrum menunjukkan ciri khas misalignment yaitu dominan pada 3x rpm mesin.

Looseness yang diberikan pada disk bearing housing outboard memberikan pengaruh yang kecil pada nilai vibrasi di grafik spektrum. Walaupun perubahan nilai vibrasi pada spektrum yang disebabkan oleh adanya cukup kecil, akan tetapi looseness akan menyebabkan perubahan pattern vibrasi pada spektrum. Pattern spektrum vibrasi yang berubah akibat adanya looseness terjadi pada bearing disk inboard dan outboard arah axial, yaitu dengan munculnya peak nonharmonic pada 3,58x rpm mesin.

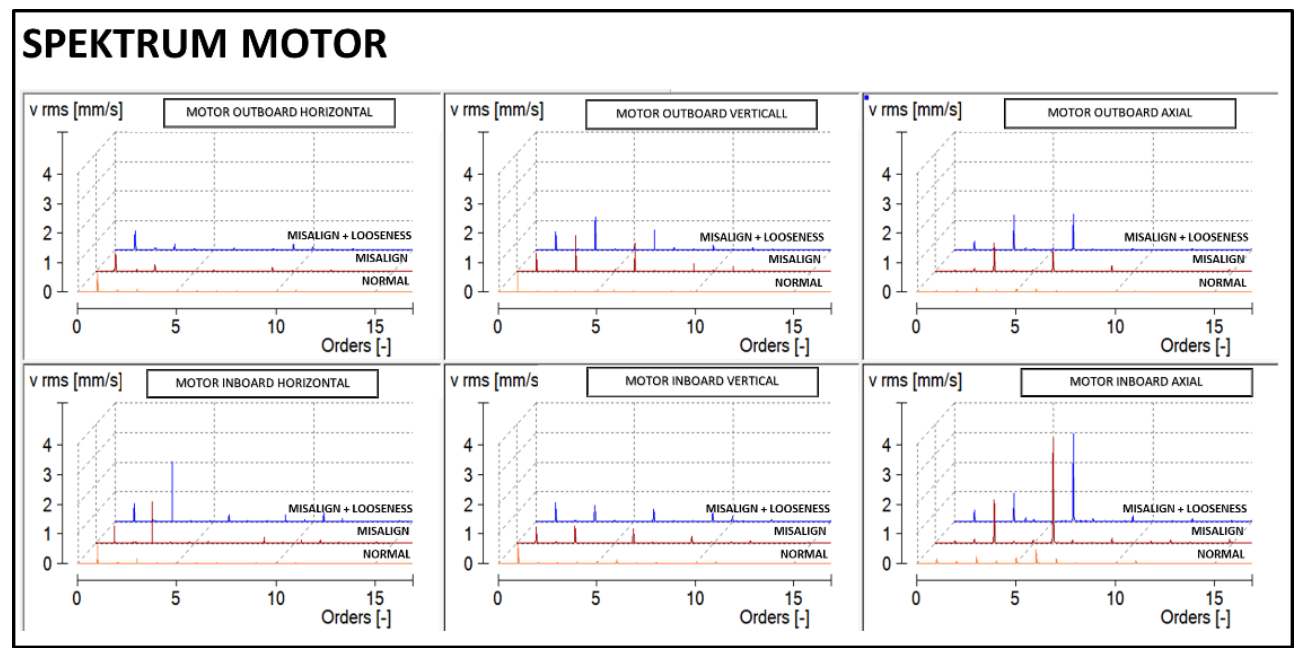

Gambar 6. Grafik spektrum motor kondisi normal, misalignment dan looseness 


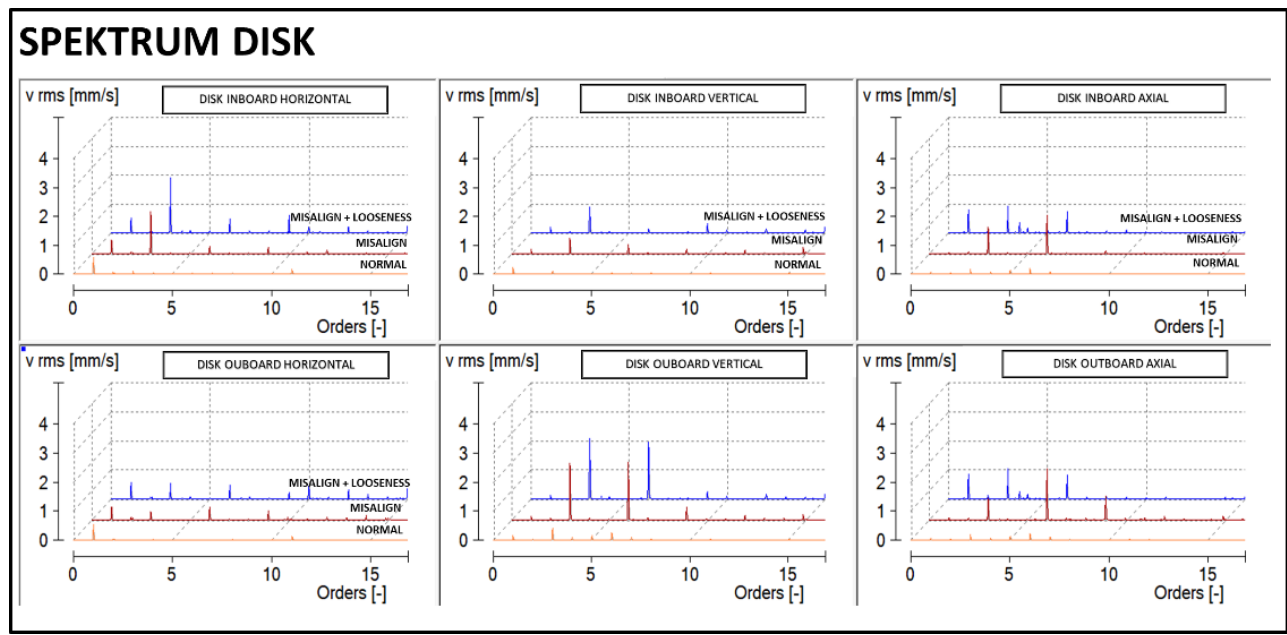

Gambar 7. Grafik spektrum disk kondisi normal, misalignment dan looseness

\section{KESIMPULAN}

Unbalance dan misalignment pada mesin akan menaikkan nilai vibrasi dengan pattern vibrasi yang khas pada spektrum. Unbalance memiliki peak dominan 1x rpm pada spektrum, sedangkan misalignment memiliki peak dominan pada 3x dan 6x rpm mesin. Looseness pada mesin yang mengalami unbalance dan misalignment akan mempengaruhi nilai vibrasi overall dan pattern vibrasi pada spektrum. Looseness pada mesin yang mengalami unbalance akan menurunkan nilai vibrasi overall dan nilai vibrasi pada spektrum, sedangkan pattern vibrasi pada spektrum tidak mengalami perubahan. Sementara itu looseness pada mesin yang mengalami misalignment akan menurunkan nilai vibrasi overall tertinggi, akan tetapi hanya memberikan pengaruh yang kecil pada nilai vibrasi pada spektrum. Pada kasus misalignment, looseness akan memberikan pengaruh pada pattern vibrasi di spektrum yaitu munculnya peak non harmonic. Berdasarkan hasil eksperimen tersebut, dapat diambil kesimpulan bahwa looseness yang terjadi pada mesin yang mengalami unbalance dan misalignment dapat merubah nilai vibrasi overall maupun pattern vibrasi pada spektrum.

\section{DAFTAR PUSTAKA}

[1] J. E. Berry, Predictive Maintenance and Vibration Signature Analysis I. Technical Associates of Charlotte, P.C., 2002.

[2] S. Sutar, V. Warudkar, and R. Sukathankar, "Vibration analysis of rotating machines with case studies," Int. J. Sci. Technol. Res., vol. 7, no. 7, pp. 70-76, 2018.

[3] M. A. Saleem, "Detection of Unbalance in Rotating Machines Using Shaft Deflection Measurement during Its Operation," IOSR J. Mech. Civ. Eng., vol. 3, no. 3, pp. 08-20, 2012.

[4] G. K. Yamamoto, C. da Costa, and J. S. da Silva Sousa, "A smart experimental setup for vibration measurement and imbalance fault detection in rotating machinery," Case Stud. Mech. Syst. Signal Process., vol. 4, pp. 8-18, 2016.

[5] B. K. Kumar, G. Diwakar, and M. R. S. Satynarayana, "Determination of Unbalance in Rotating Machine Using Vibration Signature Analysis," Int. J. Mod. Eng. Res., vol. 2, no. 5, pp. 3341533421, 2012.

[6] P. Vinh Dang, L. H. Toan Do, N. Thanh Vo, T. Nghi Ngo, and H. Nam Le, "Identification of 
Unbalance in Rotating Machinery Using Vibration Analyse Solution,” IOP Conf. Ser. Mater. Sci. Eng., vol. 841, no. 1, 2020.

[7] A. Yanto, "Studi Eksperimental Getaran Sistem Poros-Rotor Akibat Imbalance Experimental Study of Vibration of Shaft-Rotor System Due to Imbalance," vol. 7, no. 2, 2017.

[8] M. Senthilkumar and S. Sendhilkumar, "Experimental Study on the Effects of Misalignment in a Rotor- Bearing System,” AENSI, vol. 10, no. 6, pp. 89-93, 2016.

[9] A. Kurniawan, "Respon Vibrasi Overall dan Temperatur Komponen Mesin Terhadap Misalignment Axial," KILAT, 2020.

[10] H. F. Wang and G. Chen, "Asynchronous vibration response characteristics of connectors with looseness fault and its verification," Gongcheng Lixue/Engineering Mech., vol. 33, no. 4, pp. 225232, 2016.

[11] G. Yang, C. Che, S. Xiao, B. Yang, T. Zhu, and S. Jiang, "Experimental Study and Life Prediction of Bolt Loosening Life under Variable Amplitude Vibration," Shock Vib., vol. 2019, 2019.

[12] H. Wang et al., "Characteristics analysis of rotor-rolling bearing coupled system with fit looseness fault and its verification,” J. Mech. Sci. Technol., vol. 33, no. 1, pp. 29-40, 2019.

[13] M. Nataraj and G. Baskaran, "Experimental Investigation of Misalignment and Looseness in Rotor Bearing System using Bartlett Power Spectral Density," Exp. Investig. Misalignment Looseness Rotor Bear. Syst. using Bartlett Power Spectr. Density, vol. 76, no. 5, p. 313, 2017.

[14] S. Wei, W. Lu, and F. Chu, "Speed characteristics of disk-shaft system with rotating part looseness," J. Sound Vib., vol. 469, 2020.

[15] X. An and F. Zhang, "Pedestal looseness fault diagnosis in a rotating machine based on variational mode decomposition," Proc. Inst. Mech. Eng. Part C J. Mech. Eng. Sci., 2017. 